\title{
HOBBES SOBRE LA LIBERTAD DE LOS SÚBDITOS
}

\author{
Patricia Springborg \\ Centre for British Studies \\ Humboldt University, Alemania
}

\begin{abstract}
REsumen: Solo recientemente, quizás a causa de la amenaza del populismo moderno, se ha observado muy agudamente que el problema de la libertad para Hobbes se convierte casi de inmediato en el problema de la anarquía. Así, tenemos una serie de libros recientes que abordan la teoría del Estado y la anarquía de Hobbes, entre ellos Images of Anarchy, The Rhetoric and Science in Hobbes's State of Nature de Ioannis D. Evrigenis (2014), Before Anarchy de Theodore Christov (2015), Popular Sovereignty in Early Modern Constitutional Thought de Daniel Lee (2016) y From Humanism to Hobbes: Studies in Rhetoric and Politics de Quentin Skinner (2018). Este último sostiene que la descripción de Hobbes del estado de naturale-
\end{abstract}

\footnotetext{
Patricia Springborg es politóloga de la Universidad de Canterbury en Nueva Zelanda y doctora de la Universidad de Oxford. Ha enseñado ciencia política en Nueva Zelanda, en la Universidad de Pennsylvania, en la Universidad de California, Berkeley, y en la Universidad de Sydney, donde tuvo la cátedra de Teoría Política en el Departamento de Gobierno antes de ser nombrada profesora ordinaria en la Escuela de Economía de la Universidad Libre de Bolzano. Ha sido becaria del Woodrow Wilson Centre for International Scholars en Washington DC, del Wissenschaftskolleg de Berlín, del Swedish Collegium for Advanced Study en Uppsala; fue Senior Visiting Research Fellow en el St. John's College, Oxford, y recibió el Premio John D. and Catherine T. MacArthur en International Peace and Security. Como teórica política ha trabajado en un amplio rango de materias, desde teoría del Estado, historia de pensamiento político, hasta teoría democrática, teoría feminista, economía política y orientalismo. Ha publicado cuatro libros como autora, cuatro libros editados y cerca de setenta artículos en revistas referadas y colecciones editadas. Email: springbp@hu-berlin.de.
} 
za como un estado anárquico es exagerada, incluso para sus propios estándares, pero la exagera para mostrar a los panfletistas que está parodiando. Estos fueron los panfletos de Londres del lado parlamentario, que repitieron algunos de los argumentos más exagerados a favor de la soberanía popular de los hugonotes franceses radicales, a quienes Hobbes estaba preocupado de refutar desesperadamente. La razón por la que Hobbes insiste en que la persona del Estado es artificial, el trono del poder, es porque tal persona está moldeada y no preexiste al contrato social que la crea. No es la colectividad de la gente, que existe solo como una multitud desagregada antes del contrato, ni es la persona del soberano, que es simplemente su representante. La persona del Estado debe ser artificial y abstracta, porque si fuera la colectividad del pueblo, su teoría del Estado consagraría la soberanía popular, y si fuera la persona del soberano, consagraría el absolutismo monárquico, y esto Hobbes no lo hará.

Palabras Clave: Hobbes, persona artificial, libertad natural, libertades civiles, liberi homini, Skinner, republicanismo, teoría del Estado, teoría política

RECIBIDO: diciembre 2018 / ACEPTADO: abril 2019

\section{HOBBES ON THE LIBERTY OF SUBJECTS}

ABSTRACT: Only recently, driven perhaps by the menace of modern populism, it has been so acutely observed that the problem of freedom is for Hobbes almost immediately converted into the problem of anarchy. Thus we have a spate of recent books on Hobbes's theory of the State and anarchy, including Ioannis D. Evrigenis' (2014) Images of Anarchy. The Rhetoric and Science in Hobbes's State of Nature, Theodore Christov's (2015) Before Anarchy, Daniel Lee's (2016) Popular Sovereignty in Early Modern Constitutional Thought, and Quentin Skinner's (2018) From Humanism to Hobbes: Studies in Rhetoric and Politics. Skinner argues that Hobbes's depiction of the state of nature as anarchic is exaggerated, even by his own standards, but that he overplays it in order to show up the pamphleteers he is parodying. These were London pamphlets on the parliamentary side, which parroted some of the most exaggerated arguments for popular sovereignty of the radical French Huguenots, whom Hobbes was desperately concerned to refute. The reason why Hobbes insists that the person is artificial, the seat of power, is because the person of the State is crafted, and does not preexist the social contract that brings it into being. It is neither the collectivity of the people, who exist only as a disaggregated multitude before the contract, nor is it the person of the sovereign, who is merely its representative. The person of the State must be artificial and it must be abstract, because if it were the collectivity of the people his theory of the State would enshrine 
popular sovereignty, and if it were the person of the sovereign it would enshrine monarchical absolutism, and this Hobbes will not do.

KEYwords: Hobbes, artificial person, natural liberty, civil liberties, liberi homini, Skinner, republicanism, State theory, political theory

Received: December 2018/AccePted: April 2019

\section{LA LIBERTAD COMO ANARQUÍA EN LA TEORÍA DEL ESTADO DE HOBBES}

Q ue la libertad flota en las alas de la teoría del Estado de Hobbes es algo que está claro desde una sorprendente anticipación presente en la breve Epístola Dedicatoria al Leviatán, donde declara al Estado inglés "amenazado por quienes reclaman una libertad demasiado grande [es decir, los parlamentarios] y, en el lado contrario, por quienes reclaman demasiada autoridad [es decir, los realistas]", observando que "se hace difícil cruzar indemne ante las armas de ambos bandos" (L., sig. A2v/2). ${ }^{1}$ Hobbes deja en claro, sin embargo, dónde se encuentran sus simpatías: "Pienso, con todo, que la aspiración de hacer progresar el poder civil no debe ser condenada por éste; y al censurarlo las personas privadas, tampoco declaran que ese poder sea demasiado grande". En un repentino cambio de marcha, Hobbes opta por una solución estructural: "no hablo de los hombres, sino (en abstracto) del trono del poder", caracterizando su propio rol, juguetonamente, de una manera que no se repite en ningún otro lugar, de modo similar al de los gansos capitolinos que, alertando a la Asamblea, salvaron a Roma de los galos al generar un tremendo alboroto:

No hablo de los hombres, sino (en abstracto) del trono del Poder (como a aquellas criaturas simples e imparciales del Capitolio romano, que con su clamor defendían a quienes se encontraban allí por el hecho de estarlo y no atendiendo a sus personas), sin ofender a nadie

\footnotetext{
${ }^{1}$ Las citas de Leviatán corresponden a Thomas Hobbes, Leviathan [1651], with selected variants from the Latin edition of 1668, editado por Edwin Curley (1994), con referencias al capítulo (números romanos en minúscula), sección (§), paginación de la edición Head/y de la edición Curley. También se hace referencia a la edición de Richard Tuck, edición revisada para estudiantes (1996). Las citas en castellano son de la edición de Carlos Moya y Antonio Escohotado (1979).
} 
- según creo- excepto a los de fuera o a los de adentro inclinados a su favor. $(L ., \operatorname{sig} \mathrm{A} 2 \mathrm{v} / 2)^{2}$

No es casualidad que sea contra los galos que Hobbes esté defendiendo el 'trono del poder', ya que Francia es la fuente de la teoría antimonárquica y, de hecho, monarcómaca (matar al rey), a la que está atacando. Tampoco es sorprendente saber que el tremendo alboroto dentro del parlamento era casi igual a la anarquía que había afuera. Aquí, en pocas palabras, tenemos la tesis de Leviatán. Solo de manera reciente ha sido muy agudamente observado, quizás bajo el impulso de la amenaza del populismo moderno, que el problema de la libertad para Hobbes se convierte casi de inmediato en el problema de la anarquía. ${ }^{3}$ El magistral libro From Humanism to Hobbes: Studies in Rhetoric and Politics, de Quentin Skinner (2018), sostiene que la descripción de Hobbes del estado de naturaleza como anárquico es exagerada, incluso para los estándares de Hobbes, pero que la exagera para avergonzar a los panfletistas que está parodiando. Estos eran los panfletos de Londres de la década de 1640 del lado parlamentario, ahora recopilados en la extensa Colección Thomason que comprende unos 22 mil artículos guardados en la Biblioteca Británica, algunos de los cuales deben haber llegado a París, donde Hobbes se había unido a la Corte Estuardo en el exilio, y repitió como loro algunos de los argumentos más exagerados a favor de la soberanía popular sostenidos por los radicales hugonotes franceses, ¡a quienes Hobbes estaba desesperadamente preocupado por refutar!

El contraste entre la anárquica 'guerra de todos contra todos' en el estado de naturaleza, y la libertad de vivir en paz, que introdujo el contrato social, ¡enmarca la dicotomía que Hobbes inventó para prevenir la anarquía! Se une a la bandada de gansos capitolinos para protestar contra los defensores de la anarquía desde dentro de la política, así como desde afuera, reconociendo el papel desempeñado por el estado

\footnotetext{
${ }^{2}$ Livio (5.47) y Plutarco, en su Vida de Camilo, ambos cuentan la historia de los gansos capitolinos, pero la fuente más probable de Hobbes es el epítome de la historia romana de Floro, dado que Chatsworth MS DI, un libro de dictados usado por Hobbes para sus cargos de Cavendish, contiene pasajes del libro I de Floro, incluida esta historia (ver Hoekstra, 2004, n. 48).

${ }^{3}$ Ver la avalancha de libros recientes sobre la teoría del Estado y la anarquía de Hobbes. Esta incluye obras de Evrigenis (2014), Christov (2015), Lee (2016) y Skinner (2018).
} 
de naturaleza, tanto antes como después de la estatalidad: antes, como el estado de anarquía desde el cual el Estado es construido; y después, como las condiciones externas siempre presentes de la anarquía en la esfera internacional, en las cuales amenaza recaer.

La razón por la que Hobbes insiste en que la persona es artificial, el trono del poder, es porque la persona del Estado está moldeada y no preexiste al contrato social que le da nacimiento. No es ni la colectividad de las personas, que existe solo como una multitud desagregada previo al contrato, ni es la persona del soberano, que es simplemente su representante. La persona del Estado debe ser artificial y debe ser abstracta, porque si fuera la colectividad del pueblo, su teoría del Estado consagraría la soberanía popular: quienes reclaman una libertad demasiado grande; mientras que la persona del soberano consagraría el absolutismo monárquico: quienes reclaman, por el contrario, demasiada autoridad; y esto Hobbes no lo hará.

Al escribir Leviatán en París, en la década de 1640, durante la guerra civil en Inglaterra y después de las guerras de religión francesas, Hobbes prestó especial atención a los peligros de la soberanía popular y a las ideas de los radicales hugonotes franceses. Hobbes contó con Bodin para obtener municiones contra ellos, porque los radicales hugonotes franceses o monarcómacos fueron el blanco de Bodin antes de que fueran el suyo, y Hobbes lo cita. Pero Bodin no llegó a la formulación por medio de la cual Hobbes pudo esquivar a los defensores de la soberanía popular con la persona artificial del Estado. Para eso Hobbes se remontó a la historia y a la formulación papal de Inocencio IV, quien, al enfrentar el desafío de las órdenes religiosas autónomas, fue capaz de demostrar que la persona ficticia (persona ficta), que constituía las corporaciones subordinadas tales como los colegios universitarios y las órdenes religiosas (universitates), creaba una persona en derecho que podría demandar y ser demandada. Era de esta persona ficta que los hugonotes franceses se habían apropiado para el populus, haciendo del pueblo la gran universitas. Y era la misma persona ficta la que el papado presentó en su defensa de manera que los miembros de las órdenes religiosas incluso no nacidos pudieran ser excomulgados bajo los términos del Interdicto. ${ }^{4}$

\footnotetext{
${ }^{4}$ Hobbes participó personalmente en la traducción de las Cartas de Fulgenzio Micanzio a su Patrón, William Cavendish, en relación a los puntos de vista de Paolo Sarpi sobre el Interdicto Veneciano (como lo comenta Christov 2015), ¡lo que significaba que este no era un asunto puramente abstracto!
} 
Vale la pena hacer un esfuerzo considerable por demostrar que los conceptos de Hobbes del 'trono del poder' y la 'persona artificial del Estado' no son simplemente términos técnicos idiosincráticos, sino que parecen haber estado en uso durante unos cuatrocientos años antes de que él los invocara. A este respecto, su solución institucional al problema de la anarquía, que le permite mantener un camino entre los arrecifes gemelos de la Libertad y la Autoridad, no es tan artificiosa como generalmente se nos hace creer. Que él se incline a exagerar los peligros de la libertad, como anota tan perspicazmente Skinner, su teoría del estado de naturaleza como libertad que se transforma en anarquía inmoderada, surge sin duda de su preocupación por el impulso institucional para la impermeabilidad del Estado bajo la creciente presión de los acontecimientos que se desarrollan en el período previo a la guerra civil.

No hay duda de que donde Hobbes más revisa su teoría es respecto del concepto de libertades, produciendo un creciente estrechamiento en el alcance de la libertad entre sus tres obras políticas. De esta manera, la libertad, alguna vez definida en los Elementos por el principio del derecho romano, liber non servus, un hombre libre no es un esclavo, se convierte en De Cive (Hobbes 1998), en un principio cinético de "libertad de movimiento" física, sin consideración de la libertad y la esclavitud, mientras que "la libertad de los súbditos", el asunto del Capítulo 21 del Leviatán, comienza definiendo la libertad como "la falta de oposición (por oposición quiero decir impedimentos externos al movimiento); y puede aplicarse a criaturas irracionales e inanimadas no menos que a las racionales":

Y lo mismo acontece con todas las criaturas vivientes mientras están aprisionadas o en cautiverio, limitadas por muros o cadenas; y con el agua mientras está contenida por diques o canales, cuando en otro caso se desparramaría sobre una extensión mayor. Solemos entonces decir que tales cosas no están en libertad para moverse como lo harían sin esos impedimentos externos. (L., xxi, §1, 108/136)

Al definir la libertad como una propiedad que disfrutan no solo los demás animales, sino también los objetos materiales como el agua y, por lo tanto, consistente con la necesidad, Hobbes está planteando un terreno extremo que ya había desarrollado en su disputa con Bramhall 
(English Works IV, 229-278, y English Works V), como señala Curley (L., xxi, §1, 108/136, n. 1). Con un sutil ejercicio en análisis lingüístico, Hobbes avanza al distinguir entre libertades y poderes, declarando que "cuando el obstáculo al movimiento está en la constitución de la cosa misma no solemos decir que le falta la libertad, sino el poder para moverse", una vez más refiriéndose a las propiedades de los objetos inanimados así como de los animados ("como cuando una piedra yace quieta, o un hombre es atado a su cama por una enfermedad") (L., xxi, $\S 1,108 / 136)$.

Hobbes demuestra su coherente corporalismo cuando insiste en que, en consecuencia, "un hombre libre es quien en las cosas que por su fuerza o ingenio puede hacer no se ve estorbado en realizar su voluntad", haciendo hincapié en que "cuando las palabras libre y libertad se aplican a cosas distintas de cuerpos se comete un abuso, pues lo no sujeto a movimiento no está sujeto a impedimento" (L., xxi, §2, 108/136). Hobbes desnaturaliza la facultad aristotélica de la voluntad, dejando claro que:

por el uso de la palabra libre albedrío no puede inferirse ninguna libertad de la voluntad, del deseo o de la inclinación, sino la libertad del hombre, que consiste en no encontrar alto alguno a la hora de llevar a cabo lo que tiene la voluntad, el deseo o la inclinación de hacer. (L., xxi, §2, 108/136)

No nos cabe ninguna duda de que el relato de Hobbes sobre la libertad de los súbditos se basa en su ontología materialista, explicada en el capítulo xlvi del Leviatán, en términos inequívocos:

El mundo (no quiero decir solamente la Tierra... sino el universo, es decir, toda la masa de las cosas existentes) es corpóreo, es decir, cuerpo; y tiene las dimensiones de la magnitud, a saber: longitud, anchura y profundidad. Igualmente, cada parte del cuerpo es del mismo modo cuerpo y tiene esas mismas dimensiones; y, en consecuencia, cada parte del universo es cuerpo, y lo que no es cuerpo no forma parte del universo. Y puesto que el universo es todo, aquello que no forma parte de él es nada y, en consecuencia, ninguna parte. (L., xlvi, §15, 371/459) 


\section{HOBBES Y EL PROBLEMA DE LA LIBERTAD}

El concepto de libertad de Hobbes es profundamente problemático, no solo por el marco determinista en el que se asienta, señalado tan tempranamente por su debate sobre la libertad y la necesidad con el obispo Bramhall en 1645. Ni siquiera está claro en qué lugar de la tradición del pensamiento occidental sobre la libertad ubicarlo, y mucho menos cómo reconciliarlo con una metafísica determinista.

Quentin Skinner, en una serie de elegantes ensayos y libros que incluyen sus seminales Hobbes and the Proper Signification of Liberty (1990), Liberty before Liberalism (1998) y ahora Hobbes and Republican Liberty (2008), ${ }^{5}$ ha tomado el concepto de libertad de Hobbes como su tema, trazando su desarrollo como una serie de respuestas a las posiciones predominantes que tanto las incorporan como las superan. La dedicación de Skinner a la investigación de las estrategias retóricas de Hobbes ha dado algunos frutos inusuales. No solo vemos los enormes problemas que Hobbes se impuso al proceder como lo hizo, sino que el cuidadoso análisis de Skinner nos permite trazar el ingenio de Hobbes al intentar mantener un camino entre la Caribdis del determinismo y la Escila del voluntarismo - no muy exitosamente, como veremos.

El hecho de que Hobbes se sintiera obligado a lidiar con este concepto que se ajusta de manera tan incómoda en su sistema metafísico, puede ser más producto de un accidente que de un plan. En cuanto protegido de un cortesano, el conde de Newcastle le encargó que escribiera su primera pièce d'occasion sobre la soberanía indivisa asentada en el Parlamento Corto de 1640. The Elements of the Law Natural and Politic era quizás un tema que, como sugiere Deborah Baumgold, en este punto, Hobbes estaba menos preparado para tratar. ${ }^{6}$ Pero después de

\footnotetext{
${ }^{5}$ Salvo del artículo de 1990, hay versiones en castellano de las obras mencionadas de Skinner. Ver referencias.

${ }^{6}$ Deborah Baumgold (2008) argumenta que el peculiar método de Hobbes de composición en serie e inserción de nuevo material en un esquema esqueleto preparado, conduce a inconsistencias, pero también permite un tipo de deconstrucción arqueológica en la que podemos ver el desarrollo del sistema de Hobbes en términos de aquellas partes que son más completas, prefigurando su sistema maduro y aquellas que son menos completas. Ver también mi réplica, junto con la respuesta de Baumgold, en Springborg (2009).
} 
recurrir apresuradamente a Bodin, ${ }^{7}$ uno de los raros casos en que reconoce sus fuentes, Hobbes encuentra algo que lo pone en la senda de sus grandes obras políticas, De Cive y Leviatán. ¿Por qué la libertad sería una cuestión crítica? Para empezar, el contexto de Elementos planteó los problemas del electorado, ya sea del lado del parlamento o del rey sobre el impuesto de navíos o dinero para los barcos (ship money), y los problemas del electorado implican una elección, que a su vez presupone la libertad. Las fuentes de la soberanía indivisa también plantean cuestiones fundamentales de la libertad: ¿la soberanía reside en última instancia en la gente que puede transferirla voluntariamente a un soberano, o es del rey por derecho divino? Hobbes responde a esta pregunta con una parábola extendida, la transición del estado de naturaleza a la sociedad civil a través del contrato social. Pero la misma parábola que él elige, optando por una forma fuerte de voluntarismo que no se ajusta nada bien con su metafísica determinista, hace que el problema sea más difícil de resolver.

Dos tradiciones de la libertad singularmente diferentes caracterizan el pensamiento político occidental, y aparecen una después de otra, dejando de lado las tradiciones deterministas que niegan la libertad, a las cuales Hobbes en propiedad pertenece. La primera es tan antigua como la Ley Romana de las Doce Tablas en el siglo IV a. C., ${ }^{8}$ pero se expresa más sucintamente en el Digesto de Justiniano, en los pasajes iniciales que tratan De statu hominum: "La primera y principal división de personas que hace el derecho es esta: todos los hombres o son libres o son siervos". ${ }^{9}$ La noción de la libertad como estar libre de la dominación, que Skinner, Pettit ${ }^{10}$ y otros ubican como el corazón del republicanismo o la libertad romana, es, sugiero, una traducción

\footnotetext{
${ }^{7}$ Hobbes (1969), The Elements of the Law Natural and Politic, 27.7, 172-73; señalado en Skinner $(2008,60)$, citando a Jean Bodin $(1576,2.1 .219)$ [hay versión castellana en Bodin (1997)]. Skinner $(2008,192)$ menciona que la deuda de Hobbes con Bodin respecto del poder de los soberanos sobre los súbditos es "que los mantenga en el temor" (L., xvii, §13, 88/109), citando a Bodin $(1606, \S 6.4,706)$ [hay versión castellana en Hobbes (1979)] según la traducción de Richard Knolles.

${ }^{8}$ Para una explicación de la libertad bajo la República Romana, ver Springborg (2001).

9 "Summa itaque de iure personarum divisio haec est, quod omnes homines aut liberi sunt aut servi", Digest of Justinian $(1985,1.5 .3,15)$ [hay versión castellana en El Digesto del Emperador Justiniano (1872-1874)]; Skinner (2008, x).

${ }^{10}$ Ver principalmente Pettit (1997) [hay versión castellana en Pettit (1999)].
} 
libre del primer principio del derecho romano, liber non servus: "un hombre libre es aquel que no es esclavo". Tal era una distinción apropiada para una sociedad esclavista, y decir que esta distinción primaria caracteriza a todas las sociedades esclavistas es más o menos tautológico. La libertad, en consecuencia, consiste en el disfrute de "su poder sobre sí mismos" que los hombres libres, a diferencia de los que viven "bajo el poder de un dueño", y sujetos a su voluntad, disfrutan. ${ }^{11}$ Skinner, de esta manera, define "el nervio de (...) la teoría republicana" como "esa libertad dentro de las asociaciones civiles" que "es subvertida por la sola presencia del poder arbitrario, cuyo efecto es reducir a los miembros de tales asociaciones del estatuto de hombres libres al de esclavos" (Skinner 2008, x). ${ }^{12}$

Pero surgió una tradición posterior de libertad, evidente en Rousseau, por ejemplo, y deudora de los estoicos, a quienes Hobbes, por otra parte, tanto les debe. En esta tradición, la libertad es la capacidad de erigir un principio de comportamiento y seguirlo; un concepto de libertad que no presupone una sociedad esclavista; más bien lo contrario, y que por tanto no toma como primaria la distinción hombre libre/ esclavo, sino que se dedica a las consecuencias morales de la libertad para el autor-agente. La noción de libertad subjetiva pone énfasis en el poder de la voluntad de elegir el bien sobre el mal, incluso en contra de los intereses de uno, debiendo mucho al pietismo (representando así la duradera deuda de Rousseau con la Ginebra calvinista) y culminando con Kant. Era una noción a la que Hobbes no podía acomodarse y a la que no se acomodaría, ni lo hubiera soñado, enfrentándose a su determinismo. Una idea tan heroica de libertad, expresada de manera característica en actos superogatorios, sería para Hobbes positivamente peligrosa, como la raíz del derecho de resistencia y otras formas de comportamiento contraproducente. En cualquier caso, quedaba fuera de su alcance por su psicología mecanicista y por la forma en que definía la voluntad.

11 “[cives Romani] sunt suae potestatis (...) [non] sunt in aliena potestate”, Digest of Justinian (1985, 1.6.4, 18); Skinner (2008, x).

${ }^{12}$ Mucho resulta en la noción de 'poder arbitrario', como veremos más adelante. 


\section{LIBERTAD NATURAL Y DERECHO NATURAL EN LOS ELEMENTOS}

En aspectos fundamentales de The Elements of the Law Natural and Politic, Hobbes (1969) comparte la generalidad de la tradición del derecho civil romano, planteando una distinción primaria entre libertad y esclavitud, la cual también pertenece al republicanismo clásico, con su énfasis en la libertad de la dominación. Y, sin embargo, Hobbes es el enemigo del republicanismo clásico, creyendo que es la ideología de esos "caballeros democráticos" a los que reprobó en Behemoth (Hobbes 1990, 39) por hacer descender la guerra civil y el regicidio sobre las cabezas de los ingleses. Aunque Hobbes rechaza la inferencia que la teoría republicana clásica extrae de la distinción liber non servus, se mantiene, sin embargo, dentro del paradigma. Para él también la libertad es un status, o distinción espacial, que denota zonas distintivas de comportamiento: una, la de los esclavos, muy restringida; la otra, la de los hombres libres, relativamente sin restricciones. Pactar la obediencia a un soberano, especialmente en el caso extremo de sometimiento del vencido a un vencedor, tiene su análogo en el hombre libre que se entrega a la esclavitud, y Hobbes llega a ver un continuo entre estos diferentes estados de sujeción, pero en que uno está demarcado por la ley. En cada caso, los hombres pierden su capacidad para la libertad natural: el esclavo, al ser esclavizado, pierde la capacidad de actuar; el hombre libre, al pactar, pierde el derecho a actuar.

Hasta aquí todo bien, y como Richard Tuck (1979) ha demostrado adecuadamente, Hobbes se encuentra dentro de la tradición jurídica romana del derecho natural como fue más tarde cooptada por la Iglesia como derecho natural. Pero la doctrina de la libertad de Hobbes tropieza contra un problema mucho mayor cuando se confronta con su materialismo, el cual sirve para socavar los conceptos más básicos del derecho romano y, en verdad, todas las entidades metafísicas y las ideas abstractas. El materialismo de Hobbes es tal que la 'materia en movimiento', que en los humanos toma la forma de la circulación de la sangre y la biología corpuscular, produce la acción en una forma moralmente neutral. La voluntad es el último apetito de las sensaciones que empujan contra el impulso del miedo. ${ }^{13}$ Es racional únicamente en

${ }^{13}$ Hobbes (1969, 12.2, 61-2); Skinner (2008, 20). 
el sentido moderno de la racionalidad: al ser el resultado eficiente de un proceso causal. Las leyes de la razón natural, si son en efecto más que las máximas de la autoconservación, simplemente corresponden a cálculos de medios y fines, infalibles solo en el sentido de que son deducidas con certeza. Nos queda la opción de interpretar la afirmación de Hobbes de que la libertad y la servidumbre apoyan una falsa antítesis - porque el movimiento de los cuerpos políticos es simplemente una continuación del movimiento de los cuerpos naturales-, o bien, interpretarla como un argumento analógico detrás del cual yace una paradoja que aún no se ha resuelto.

El hecho de que Hobbes tome en serio la antítesis entre el estudio de los cuerpos naturales y el de los cuerpos políticos, nos lo señala la publicación por separado (sea autorizada por Hobbes o no, ciertamente) de Elementos de derecho en las dos partes en las que está organizado: Naturaleza humana, publicada en febrero de 1650, que establece en 13 capítulos "todo lo referente a la naturaleza humana, que consiste en las capacidades naturales del cuerpo y de la mente"; y De corpore politi$c o$, publicado tres meses después, en el que busca demostrar cómo los hombres así constituidos pueden lograr "garantía suficiente para su paz común" (Skinner 2008, 18). Hobbes asume que el estudio de los cuerpos naturales y políticos toma una senda dual. El estudio de los cuerpos políticos, que se llama filosofía civil, ${ }^{14}$ procede por la definición de los términos para "establecer unos principios básicos tales que, al no inspirar desconfianza a la pasión, no se intente desplazarlos" (Hobbes 1969, xv; Skinner 2008, 19). Dado que la generación de ideas, como reflejo de las sensaciones (Hobbes, L., cap. 1, Del sentido), pertenece al sustrato materialista de la acción, es difícil ver cómo las pasiones, concernientes a ese sustrato, podrían desplazar a las ideas. Pero esta es una paradoja que pertenece al cuadro mucho más grande del rol de las ideas, socavado por la psicología sensacionalista de Hobbes.

Skinner (2008, 19), citando a Baumgold (2004), comenta que es extraño, a la luz de su estrategia preferida de avanzar mediante la definición en el estudio de los cuerpos políticos, o filosofía civil, que Hobbes en ninguna parte proporcione una definición formal de libertad. Pero, una vez más, dado que Hobbes subsume la libertad bajo el libre

14 Ver el cuadro 'De las diversas materias del conocimiento', en Hobbes (1996, cap. 9, 61); Skinner $(2008,19)$. 
movimiento característico de los cuerpos naturales comprometidos en un desplazamiento perpetuo a menos que sea impedido, la libertad, estrictamente hablando, pertenece al sustrato materialista de los cuerpos naturales, y en absoluto a la superestructura de los cuerpos políticos. En consecuencia, la primera discusión de Hobbes sobre la libertad humana se coloca al final de su discusión sobre los poderes de la mente, en la que describe los requisitos previos para la acción humana como la "libertad de hacer o no hacer" (Hobbes 1969, 12.1, 61; Skinner 2008, 20). Consistente con las leyes de la materia en movimiento, la decisión, que pone fin a los procesos mentales de de-liberación a través de los cuales se alcanza, constituye, tautológicamente, "proceder de acuerdo con nuestra propia libertad" (Hobbes 1969, 12.1, 61; Skinner 2008, 20). En términos de su mecanismo, la deliberación es precisamente la lucha entre el empuje de nuestros apetitos, como el ímpetu (conatus) para actuar contra el impulso de nuestros miedos, que nos inmovilizaría, pues "en la deliberación, tanto el apetito final como el temor final se llaman voluntad, el apetito final de querer hacer; el temor final no hará o evitará hacer" (Hobbes 1969, 12.1, 61-2; Skinner 2008, 20).

Esta descripción difiere de la de Aristóteles sobre la conducta voluntaria solo en la presunción de Hobbes de un sustrato materialista de los "cuerpos en movimiento", en términos de la cual puede ser científicamente demostrada. No es sorprendente, entonces, que él recurra al ejemplo de Aristóteles en la Ética a Nicómaco (1110a) del hombre que "arrojó sus mercancías al mar desde el barco para salvar su persona" (Hobbes 1969, 12.3, 62; Skinner 2008, 21), como ejemplo de la situación más extrema que pueda ser causada por el impulso del miedo y el empuje de la pasión, pero que, sin embargo, puede resolverse por la decisión. También es una parábola para su distinción entre los dos caminos hacia la soberanía: pactar por temor y la soberanía por adquisición o por conquista. El pactar por miedo, como el hombre que arroja sus bienes por la borda para evitar el naufragio, "no es más en contra de su voluntad, que el huir del peligro es contra la voluntad de quien no ve otro medio para salvarse". Aunque aparentemente se actúa por compulsión, su decisión es un acto de voluntad y "completamente voluntario" (Hobbes 1969, 12.3, 62; Skinner 2008, 23).

Entonces, ya sea pactar por miedo en el estado de naturaleza como hacer tratos por la paz sometiéndose a un conquistador, son actos de deli- 
beración en los que el último apetito determina la voluntad. Demuestran el principio epicúreo y estoico de la determinación psíquica que Hobbes suscribe: la atracción del placer y la evitación del dolor. En cualquier caso, Hobbes insiste, nuestro comportamiento es igualmente el producto de la voluntad como la última acción en la cadena causal y "no existe razón para que lo que hagamos por miedo obligue menos que lo hecho por codicia" (Hobbes 1969, 15.13, 79; Skinner 2008, 23). En otras palabras, en términos de acción vinculante, respecto de la cual él está preocupado de buscar fundamentos válidos para el pacto, las sanciones negativas funcionan tanto como los incentivos positivos. En los Elementos, Hobbes tiene mucho que decir sobre el comportamiento voluntario como producto de sanciones negativas (el concepto negativo de la libertad, o libertad de, como lo haría Isaiah Berlin), pero guarda un notorio silencio sobre los incentivos positivos (lo que lleva a la libertad positiva de Berlin [1958], o poder para). En el capítulo 22, donde se ocupa de la soberanía por adquisición, Hobbes hace lo que "parece ser un error"; no obstante, al distinguir momentáneamente entre un "ofrecimiento voluntario de sometimiento", por un lado, y la "sumisión mediante compulsión", por el otro, como señala Skinner (Hobbes 1969, 22.2.127; Skinner 2008, 23) es como si él todavía no estuviera dispuesto a renunciar al entendimiento del juicio escolástico (platónico, aristotélico) como producido por la facultad de la voluntad, en favor de la noción materialista (estoica, escéptica y epicúrea), por la cual el juicio es el último movimiento de la mente, determinado por la voluntad como el último apetito.

\section{DE CIVE, LIBERTAD CIVIL Y LIBERI HOMINI}

Al preferir el modelo romano del pater familias y al hacer una audaz demostración al combinar las esferas de poder de Aristóteles, política, paternal y despótica, Hobbes en De Cive (1998) deja en claro en qué consiste la libertad del hombre libre, ya sea como súbdito, padre, hijo o siervo. Aunque defendida en el lenguaje del derecho romano, es una posición que permite restricciones más o menos ilimitadas a la libertad del ciudadano, siempre y cuando no alcancen la esclavitud (Hobbes 1998, 9.9, 167; Skinner 2008, 118). ${ }^{15}$ ¿Por qué sería esto así? Vale la pena

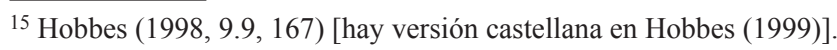


recordar que si los Elementos (1969) fue escrito como un resumen para el Conde de Newcastle en las circunstancias del Parlamento Corto, De Cive (1998) fue escrito por Hobbes en París por encargo del Príncipe de Gales y futuro Carlos II y, por lo tanto, tenía un enfoque diferente. Como un manual de política para el Príncipe, ponía a prueba los límites del absolutismo y lo que el Príncipe podría aprender acerca de las ventajas que un sistema basado en la Civil Law, en oposición a la Common Law, podría proporcionarle.

$\mathrm{Y}$ esto es precisamente lo que abarca, a mi entender, el proyecto de Hobbes: su desarrollo desde los Elementos y De Cive hasta Leviatán siempre poniendo a prueba los límites de las restricciones a la libertad consistentes con el estatuto del hombre libre como opuesto al esclavo, lo que llega a ser más y más extremo. De manera que mientras en los Elementos la distinción entre un hombre libre y un esclavo se construye positivamente, desde el punto de vista del hombre libre, en De Cive Hobbes ha adoptado una visión extrema de las restricciones que la soberanía absoluta puede imponer a los ciudadanos, cuyo alcance para el movimiento es únicamente superior al de los esclavos en el sentido de que no están encadenados, y de que todavía son técnicamente libres en tanto no estén encarcelados. Como señala Skinner: "mientras la última palabra de Hobbes en los Elementos era que los súbditos son apenas algo más libres que los esclavos, [en De Cive] él prefiere ahora enfatizar que incluso los esclavos son apenas menos libres que los súbditos" (Skinner 2008, 122, cit. Hobbes 1998, 9.9, 167). Por alguna razón, Skinner encuentra la doctrina de la libertad de Hobbes en De Cive más aceptable que la versión que la precede en los Elementos. ${ }^{16}$ Pero no puedo estar de acuerdo. Pienso que Hobbes no fue bienintencionado al tratar la libertad de los súbditos; una libertad quimérica, en cualquier caso, dada su ontología determinista. De manera que probablemente él estaba satisfecho con su éxito en reducir el alcance de la libertad en el

\footnotetext{
16 Skinner (2008, 122-23) habla de "esta inversión de énfasis" como lo que "permite a Hobbes escenificar un golpe retórico final y general" para persuadir "a los súbditos de soberanos absolutos de que ellos no están menos autorizados a pensar en sí mismos como poseedores de libertas civilis que aquellos que viven en democracias o Estados libres" y, por lo tanto, "para presentar su argumento como una teoría de la ciudadanía"; de ahí el título, De Cive. Él encuentra en De Cive "un tono de resuelta seguridad", que contrasta con "una nota conscientemente sombría" presente en The Elements sobre el tema "de libertad y sujeción" (Skinner 2008, 121).
} 
mundo epifenoménico del derecho y la ciudadanía. Creo que mi punto de vista puede ser reivindicado en términos de la creciente indignación con la que se recibió la doctrina de Hobbes a medida que progresaba a través de las tres obras. ${ }^{17}$

De Cive marca un avance confeso para Hobbes una vez que se dio cuenta de que ahora podía entregar un recuento en el que la sumisión al gobierno era compatible con la 'libertad civil' o libertas civilis (Hobbes 1998, 9.9, 167; Skinner 2008, 116). En los Elementos, la libertad civil sería un oxímoron, porque en este punto Hobbes consideraba la libertad y la sociedad civil como antitéticas. De manera que proclamó ruidosamente lo siguiente: "la libertad no puede coexistir con la sujeción" (Hobbes 1969, 27.3, 169; Skinner 2008, 54); y el estado de libertad natural "es el estado de quien no es súbdito" (Hobbes 1969, 23.9, 134; Skinner 2008, 54); mientras que el estado de sujeción civil necesariamente implica "pérdida de libertad" (Hobbes 1969, 24.2, 139; Skinner 2008, 54). En los Elementos, Hobbes incluso se refirió a la noción de liberi homines en la sociedad civil como una forma de autoengaño, argumentando que cuando un hombre "se llama a sí mismo, a pesar de estar sometido, hombre libre" (Hobbes 1969, 23.9, 134; Skinner 2008, 79-80), no pretende "sino esto: que el soberano se dé cuenta de su habilidad y de sus merecimientos y le coloque en un empleo" (Hobbes 1969, 27.3, 170; Skinner 2008, 80). Como señala Skinner, "habiendo desenmascarado la vanidad de estos autodenominados y autoengañados liberi homines, Hobbes está listo para su resumen letalmente deflacionario" (Hobbes 1969, 23.9, 134; Skinner 2008, 79-80):

La libertad equivale en las repúblicas simplemente al honor de ser tratado como igual a los demás súbditos, siendo la servidumbre la situación del resto. En consecuencia, un hombre libre puede esperar empleos de honor más que un sirviente. Y esto es todo lo que cabe entender por libertad del súbdito. Pues en todos los demás sentidos libertad es el estado de quien no es súbdito. (Hobbes 1969, xv; Skinner 2008, 19)

Letalmente deflacionario puede ser, pero el recuento de Hobbes de los liberi homines también es implacablemente consistente. En las repú-

${ }^{17}$ Ver el excelente libro de Parkin (2005). 
blicas, en las cuales todavía se aplica el principio del derecho romano liber non servus, dado que la institución del servicio contratado todavía existe, los hombres libres, a diferencia de los siervos, pueden esperar compartir igualmente los honores (también traducibles del latín como 'oficios') conferidos por el Estado. De esa manera, la libertad del súbdito en la sociedad civil vive únicamente en la aspiración a un oficio - un espacio diminuto en el siglo XVII-, ${ }^{18}$ como lo que lo diferencia de los sirvientes o esclavos.

\section{LIBERTAS CIVILIS, LEVIATÁN Y LA TRADICIÓN REPUBLICANA}

Hay ciertamente un cambio de énfasis en De Cive, donde la libertad y el sometimiento ya no son antitéticos, porque la libertad ahora se define principalmente en términos de libertad de movimiento: "La libertad de cada uno es mayor o menor, como tiene mayor libertad el que está encerrado en una cárcel más amplia que el que lo está en una angosta" (Hobbes 1998, 9.9, 167; Skinner 2008, 116-17). ${ }^{19}$ ¡Una afrenta indignante al nombre de la libertad! La libertad civil o libertas civilis ahora no es más que una cuestión de "cuántas más vías tenga alguien para moverse", y mientras más rango de movimiento tiene, "tanto mayor $l i$ bertad tendrá" (Hobbes 1998, 9.9, 167; Skinner 2008, 117); ${ }^{20}$ de lo cual se deduce que "en este sentido son libres tanto los ciudadanos como los siervos que no estén atados o encarcelados" (Hobbes 1998, 9.9, 167; Skinner 2008, 117). ${ }^{21}$ Es un argumento que Hobbes extenderá en Leviatán para insistir en que hay tanta libertad en las monarquías como en las repúblicas, y en Constantinopla como en Lucca, burlándose a la vez de orientalistas y republicanos.

\footnotetext{
${ }^{18}$ Por supuesto, Hobbes debió haber estado al tanto de la práctica de la venta de oficios en la Francia del siglo XVII y del contexto en el que fue argumentado el debate del merum imperium del derecho romano, al cual Bodin hizo una muy importante contribución (ver Gilmore 1941).

19 "Et est cuique libertas maior vel minor, prout plus vel minus spatii est in quo versatur; ut maiorem habeat libertatem qui in amplo carcere, quam qui in angusto custoditur."

20 "quo quis pluribus viis movere se potest, eo maiorem habet libertatem. Atque in hoc consistit libertas civilis".

21 "quo sensu omnes servi \& subditi liberi sunt, qui non sunt vincti, vel incarcerate".
} 
De Cive parece marcar un cambio radical con los Elementos en términos de las crecientes restricciones en el ámbito de la libertad, pero ¿podemos estar seguros de que no es simplemente una diferencia de contexto lo que explica la diferencia de énfasis? En los Elementos, dirigiéndose a los campeones de un gobierno mixto, Hobbes hizo una excepción a la regla de que la libertad era incompatible con la subordinación al gobierno, y esa era para quienes vivían en una democracia: “Tenía razón Aristóteles: la razón de ser o intención de una democracia es la libertad" (Hobbes 1969, 27.3, 170; Skinner 2008, 76). Pero me pregunto: ¿no es acaso este otro ejemplo de la ironía mortal de Hobbes? La libertad en una democracia también es una ficción: "cada individuo se convierte en un súbdito, pero el pueblo como cuerpo se convierte en portador de la soberanía", como lo señala Skinner (2008, 76, cit. Hobbes 1969, 20.3, 109). Una vez más, la exigencia de que él no habla "de los hombres, sino (en abstracto) del trono del poder" (L., sig A2v/2), significa que, incluso en el caso de la democracia, las personas deben someterse al gobierno como una institución. Solo de este modo es consistente de Aristóteles sostener que "ningún hombre puede participar de la libertad, salvo en una commonwealth popular" (Hobbes 1969, 27.3, 170; Skinner 2008, 76). En las democracias como la ateniense, el pueblo puede gobernarse a sí mismo en tanto ficción, mientras que en todos los demás casos el pueblo no pretende gobernarse a sí mismo sino más bien someterse al gobierno. De ello se sigue entonces que, "teniendo en cuenta que la libertad no puede coexistir con la sujeción", al igual que en una monarquía, "la libertad de una república radica en el gobierno y en la regla de derecho" (Hobbes 1969, 27.3, 169; Skinner 2008, 76-77). Es un pequeño paso para la afirmación de Hobbes en Leviatán según la cual no podemos deducir que el hecho de que un hombre en particular en Lucca tenga más libertad que en Constantinopla, sea solo una tautología (L., xxi, §8, 110/140; Skinner 2008, 162):

Está escrita sobre las torres de la ciudad de Lucca en grandes caracteres la palabra libertas, pero de ello nadie puede deducir que un hombre particular tiene más libertad o inmunidad por el servicio de la república allí que en Constantinopla. La libertad será idéntica si una república es monárquica o popular. (L., xxi, §8, 110/140; Skinner 2008, 162)

Y aquí Hobbes invoca su famoso argumento sobre "el silencio de la ley": ni en Lucca ni en Constantinopla el Estado puede regularlo 
todo, y donde no regula "los hombres tienen libertad de hacer lo que puedan sugerirles sus propias razones, a fin de extraer para sí lo más beneficioso" (L., xxi, §6, 108/138). ${ }^{22} \mathrm{Y}$, lo que es más importante: Hobbes continúa en la argumentación reafirmando la posición extrema de De Cive: "si tomamos libertad en el sentido adecuado, como libertad corporal, esto es, la libertad de las cadenas y de la prisión, sería muy absurdo para los hombres clamar como lo hacen por una libertad de la que tan manifiestamente disfrutan" ( $L$., xxi, $\S 6,108 / 138) .{ }^{23}$ Esto, en lo que a él concierne, resuelve de una vez el argumento sobre la libertad. En el espacio de tiempo que transcurrió entre la escritura de los Elementos y De Cive, entre el Parlamento Corto y el Parlamento Largo, se desató una guerra civil en Inglaterra y fue escrito el Leviatán a consecuencia de esto. La gran tradición del derecho público de la libertad como libertad de dominación se ha reducido a un punto de fuga. Lo que queda son las libertades privadas de la sociedad civil, la libertad de comercio, de contratar, de domicilio, de dieta, y el derecho a vivir y criar a los hijos en paz: "como acontece con la libertad de comprar y vender, y con la de contratar, elegir el propio domicilio, la propia dieta, la propia línea de vida, instruir a sus hijos como consideren oportuno y cosas semejantes" (L., xxi, §6, 108/138). ${ }^{24}$

Hobbes, en este punto, más o menos anticipa la distinción de Benjamin Constant (1995) en De la libertad de los antiguos comparada con la de los modernos, de 1819. De hecho, se podría argumentar que el propio Hobbes ya había teorizado sobre una forma moderna de liberalismo, incluso si su insistencia en la prioridad del poder estatal tiende a enmascarar sus beneficios. Escribiendo tras las secuelas de la Revolución Francesa, Constant vio la República moderna basada en la libertad civil y el Estado de derecho que ofrece una sociedad comercial

22 "Pues viendo que no hay en el mundo república donde haya suficientes reglas establecidas para la regulación de todas las acciones y palabras de los hombres (por ser una cosa imposible), se sigue necesariamente que en todo tipo de acciones, por las leyes predeterminadas, los hombres tienen libertad de hacer lo que puedan sugerirles sus propias razones, a fin de extraer para sí lo más beneficioso." Skinner (2008) no incluye esta cita.

${ }^{23}$ Skinner (2008) no incluye este argumento, ligeramente ampliado en Hobbes (1839, v3, 161).

${ }^{24}$ Skinner (2008) apunta que en el Leviatán en latín, $O L$ v3, 161, los ejemplos están eliminados. 
moderna en la que, con la abolición de la esclavitud, todos tienen que trabajar, tienen libertad de excesiva interferencia estatal y paz para disfrutar de los beneficios de la paz. Mientras que la antigua libertad de los romanos y los galos era heroica y cívica, con los ciudadanos disfrutando de una participación directa en el gobierno y un alto nivel de implicación personal, Constant creía simplemente que el mundo había cambiado:

\begin{abstract}
Pregúntense en primer lugar, señores, lo que hoy un inglés, un francés, un habitante de los Estados Unidos de América, entienden por la palabra libertad. Para cada uno es el derecho a no estar sometido sino a las leyes, de no poder ser detenido, ni condenado a muerte, ni maltratado de ningún modo, por el efecto de la voluntad arbitraria de uno o varios individuos. Es para cada uno el derecho de dar su opinión, de escoger su industria y de ejercerla; de disponer de su propiedad, de abusar de ella incluso; de ir y venir, sin requerir permiso y sin dar cuenta de sus motivos o de sus gestiones. Para cada uno es el derecho de reunirse con otros individuos, sea para dialogar sobre sus intereses, sea para profesar el culto que él y sus asociados prefieren, sea simplemente para colmar sus días y sus horas de un modo más conforme a sus inclinaciones, a sus fantasías. Finalmente, es el derecho, de cada uno, de influir sobre la administración del gobierno, sea por el nombramiento de todos o de algunos funcionarios, sea a través de representaciones, peticiones, demandas que la autoridad está más o menos obligada a tomar en consideración. Comparen ahora esta libertad con la de los antiguos. (Constant 1995)
\end{abstract}

C.B. Macpherson (1962) estaba sin duda en lo cierto al ver a Hobbes como portavoz temprano del individualismo posesivo, con su énfasis en las libertades económicas que el ciudadano todavía podría disfrutar en la esfera privada. Además, Hobbes podría incluso complacer a aquellos liberales que persisten en ver un fondo de libertad en el corazón de su doctrina, en la distinción in foro interno/in foro externo y su permisividad acerca de la creencia privada, ${ }^{25}$ siempre que uno interprete estas libertades como no más que las libertades económicas de los individuos en la esfera privada (lo que el neoliberalismo condona).

${ }^{25}$ Para una de las exposiciones más recientes de la posición liberal y la doctrina de Hobbes sobre los foros 'internos' y 'externos', ver Jaume (2007). 
¡Pero a qué costo para la libertad en la gran tradición! Hobbes nunca se aleja mucho de sus posiciones originales, pero marca un cambio de énfasis. Lo que comenzó en los Elementos de derecho como una especificación de los derechos positivos comúnmente disfrutados bajo el derecho romano, el derecho "a todas las cosas necesarias para la vida", como el derecho de servirse "del fuego, del agua, del aire libre, de un lugar donde vivir" (Hobbes 1969, 17.2, 88; Skinner 2008, 54), para el Leviatán se convierte en una especificación negativa de los límites de la libertad. La libertad ahora no es más que el derecho a las necesidades de la vida en consonancia con la autoconservación. Es difícil imaginar una definición más tacaña, ya que incluso los animales tienen este derecho. Correspondientemente, si en De Cive la libertad era simplemente la ausencia de cadenas que distinguían a un hombre libre de un esclavo — una vuelta de tuerca más_-, para el Leviatán ella está por completo vacía, no es nada más que libertad de movimiento, una reductio ad absurdum diseñada seguramente para burlarse de todos nosotros.

¿Dónde deja esto a la libertad republicana? Skinner también ve la libertad como la víctima del sistema de Hobbes, que es la bifurcación en el camino hacia el futuro. A fin de cuentas, los parlamentarios sobrevivieron indemnes y la 'mezclarquía' o el constitucionalismo liberal, como se llegó a caracterizar a los gobiernos desde la antigua Roma hasta los Estados Unidos y Francia modernos, finalmente triunfó, aunque en Gran Bretaña se dio como monarquía constitucional en lugar de como un republicanismo. En cuanto al propio Hobbes, él se convirtió perversamente en el padrino del libertarismo, esa etiqueta de la libertad definida como permitir que los individuos 'vivan como les plazca' _ iprueba suficiente de que Hobbes rara vez ha sido entendido en cuanto a la libertad! No solo los libertarios y los constitucionalistas liberales encuentran en Hobbes la errada procedencia de sus puntos de vista, sino que también persisten en ver en su distinción in foro interno/ in foro externo un gesto bienintencionado en la dirección hacia la libertad personal o hacia la libertad de creencia. De hecho, por supuesto, es todo lo contrario. Simplemente registra el pesimismo de Hobbes sobre los límites del control del soberano sobre las creencias privadas de un súbdito, por la muy buena razón de que ellas no están en el control del súbdito mismo, sino más bien en el flujo de los estímulos ambientales. Únicamente como consecuencia de la esmerada erudición de Quentin 
Skinner podemos ver la serie de nudos que Hobbes ató en nuestro concepto de libertad, con la esperanza de lograr lo que Enrique IV de Francia y su modelo, el Hércules gálico, nunca lograron, que fue atar los oídos de los súbditos a los labios de su soberano, de modo que estuvieran necesariamente constreñidos a hacer su voluntad (L., xxi, §5, 108/138; Skinner 1990, 121-51). ${ }^{26}$

Philip Pettit (1997) ha llegado a la sombría conclusión de que el análogo más cercano para el contrato social de Hobbes es el contrato entre amo y esclavo, mediante el cual el esclavo acuerda la propiedad sobre su persona, colocándose en sumisión hacia un amo "que no se supera con nada, ni siquiera con el dominio que implicaría mantenerte encadenado" (Pettit 2005, 136). Parece probable que esta sea la lectura que John Locke dio también en el Segundo tratado al contrato social de Hobbes, haciendo una especial mención a que solo un esclavo podría acordar el presupuesto mismo del contrato, la propiedad sobre la propia persona y, entonces, únicamente bajo coacción, algo que un ciudadano no podía hacer.

Es un pequeño consuelo el hecho de que Hobbes permita que los ciudadanos se parezcan más a los buenos esclavos con permiso de dejar la casa, o a los sirvientes contratados atados solo por vínculos verbales, que a los esclavos de las plantaciones atados por grilletes. Porque, como él insistió, y como Pettit ha tan bien argumentado, las limitaciones físicas a la libertad de movimiento no son peores que, y posiblemente no son tan malas como la sumisión autoimpuesta que los ciudadanos asumen al pactar el contrato social. Son simplemente diferentes. Esos lazos verbales, "cadenas artificiales, llamadas leyes civiles, ellos mismos, mediante pactos mutuos, las han soldado en un extremo a los labios de ese hombre o asamblea a quien concedieron el poder soberano, y en el otro extremo a sus propios oídos", crean una sumisión irre-

\footnotetext{
${ }^{26}$ El Hércules gálico, mencionado por Diodoro Sículo, y el retor sirio Luciano, era un gigante primitivo vestido únicamente con una piel de oso, empuñando un garrote y un carcaj, "arrastrando detrás de él a una gran multitud de hombres atados por sus orejas a su lengua"; se resaltaba así que este gigante no necesitaba garrotes, porque la retórica hacía el truco. Ver Lucian (1913, v1, 63) [hay versión castellana en Luciano (1983)]. El Hércules gálico era una característica de la iconografía tanto de Enrique II como de Enrique IV de Francia, precisamente por este atributo que Hobbes selecciona. Ver Bryant (1992) y Springborg (1995), especialmente la sección 4, Leviathan and the Gallic Hercules, 363-69 y notas.
} 
vocable de la cual no hay manumisión ( $L .$, xxi, §5, 108/138). Lo que los reyes no pudieron hacer a los hombres, según Hobbes, se lo han hecho ellos a sí mismos. ¡Aquí no hay un republicano clásico, ni un constitucionalista liberal, y ciertamente tampoco un libertario!

Esta homología contrato social/contrato de esclavos merma severamente la más o menos benigna visión de elección racional, cercana a la teoría de juegos, del contrato social como una estrategia minimax calculada por actores racionales. ${ }^{27} \mathrm{Y}$ abre un forado justo a través de la noción de libertad como un derecho santificado por la costumbre inmemorial en la tradición anglosajona de la Carta Magna, así como las convenciones de consenso, a las cuales el derecho británico temprano, como el escandinavo y más ampliamente el germánico, se conformaron. ${ }^{28}$ Aquí, donde 'la casa de uno es su castillo', la libertad denota un sentido peculiarmente individualista y psicológico de libertad de interferencia. A este respecto, la tradición del Common Law difería de las tradiciones del derecho civil romano y europeo al abstenerse precisamente de especificar la obligación legal de manera demasiado exhaustiva, mientras que en la ley codificada, donde las obligaciones están completamente especificadas, la libertad de interferencia solo se obtiene en aquellos espacios marcados por 'el silencio de la ley', como ocurre hoy. Una teoría del contrato social cuyo análogo más cercano era 'el contrato de esclavos' entregó el muy apreciado argumento a favor de la 'libertad del verdadero inglés', particularmente querido por los parlamentarios en la época de Hobbes, y más tarde por los whigs del país, ¡una regia patada en los dientes!

Vemos en las maquinaciones del Brexit — quizás la crisis constitucional más seria que ha sufrido el Reino Unido desde la guerra civil de mediados del siglo XVII- cómo las nociones de libertad se transforman en anarquía y en un libertarismo peculiarmente británico, que permite que 'mi partido, esté en lo cierto o no', pueda producir el

\footnotetext{
${ }^{27}$ La analogía contrato social/contrato de esclavos fue precisamente el argumento de Carole Pateman (1988) en The Sexual Contract; una posición que ella y Charles Mills han ampliado aún más en la noción del contrato racial. Ver Pateman y Mills (2007).

${ }^{28}$ Sobre la libertad como un derecho en la Ancient Constitution, santificada por la costumbre inmemorial, ver Pocock (1957, reimpreso en 1987) [hay versión castellana en Pocock (2011)]; y sobre un vis à vis del derecho germánico y romano, ver la introducción de Gilmore (1941) y, más en general, Harold J. Berman (1983) [hay versión castellana en Berman (1996)].
} 
caos que Hobbes estaba anticipando en su propia época, iy quizás el desastre que casi quinientos años antes se logró por tan poco evitar! La reciente avalancha de libros sobre Hobbes y la anarquía, que tratan sobre el populismo que se ha vuelto tan tóxico, ¡ha resultado ser muy oportuna!

\section{REFERENCIAS}

Baumgold, D. 2004. The Composition of Hobbes's Elements of Law. History of Political Thought 25 (1), 16-42.

Baumgold, D. 2008. The Difficulties of Hobbes Interpretation. Political Theory 36, 827-55.

Berlin, I. 1958. Two Concepts of Liberty. Oxford: Oxford. [Hay versión castellana en Berlin, I. 1995. Dos conceptos de libertad y otros escritos. Madrid: Alianza.]

Berman, H.J. 1983. Law and Revolution: The Formation of the Western Legal Tradition. Cambridge: Harvard University Press. [Hay versión castellana en Berman, J.H. 1996. La formación de la tradición jurídica de Occidente. México DF: Fondo de Cultura Económica.]

Bodin, J. 1576. Les six livres de la republique. Paris.

Bodin, J. 1606. Six Bookes of the Republique. Traducido por R. Knolles. London. [Hay versión castellana en Bodin, J. 1997. Los seis libros de la República. Madrid: Tecnos.]

Bryant, L.M. 1992. Politics, Ceremonies, and Embodiments of Majesty in Henry II's France. En European Monarchy. Its Evolution and Practice from Roman Antiquity to Modern Times, editado por H. Duchhardt, R. Jackson y D. Sturdy. Stuttgart: Franz Steiner Verlag, 127-54.

Constant, B. 1995. The Liberty of the Ancients Compared with that of the Moderns. En Political Writings, editados y traducidos por B. Fontana. Cambridge: Cambridge University Press, 307-28. [Hay versión castellana en Constant, B. 1995. Discurso sobre la libertad de los antiguos comparada con la de los modernos. En Selección de textos políticos de Benjamín Constant, editado por O. Godoy, Estudios Públicos 59, 482-99.]

Christov, T. 2015. Before Anarchy. Cambridge: Cambridge University Press.

Digest of Justinian 1985. Editado por T. Mommsen y P. Krueger. Philadelphia: University of Pennsylvania Press, 4 vols. [Hay versión castellana en El Digesto del Emperador Justiniano, editado por M. Gómez Marín y P. Gil y Gómez. Imprenta de Ramón Vicente, 1872-1874, 3 vols.]

Evrigenis, I.D. 2014. Images of Anarchy, The Rhetoric and Science in Hobbes's State of Nature. Cambridge: Cambridge University Press.

Gilmore, M.P. 1941. Argument from Roman Law in Political. Thought, 1200-1600. Cambridge: Harvard University Press. 
Hobbes, T. 1839. Opera philosophica quae latine scripsit. Editado por Sir W. Molesworth. London: John Bohn.

Hobbes, T. 1969. The Elements of the Law Natural and Politic. Editado por F. Tönnies; 2da. ed., editada por M.M. Goldsmith. New York: Barnes \& Noble. [Hay versión castellana en Hobbes, T. 1979. Elementos de derecho natural y político. Madrid: Centro de Estudios Constitucionales.]

Hobbes, T. 1990. Behemoth, or The Long Parliament [1679.] Editado por F. Tönnies. Introducción de S. Holmes. Chicago: University of Chicago Press. [Hay versión castellana en Hobbes, T. 1992. Behemoth o el Parlamento Largo. Madrid: Tecnos.]

Hobbes, T. 1994. Leviathan [1651], with selected variants from the Latin edition of 1668. Editado por E. Curley. Indianapolis: Hackett. [Hay versión castellana en Hobbes, T. 1979. Leviatán, editado por C. Moya y A. Escohotado: Editora Nacional.]

Hobbes, T. 1996. De las diversas materias del conocimiento. Leviathan. Editado por R. Tuck, edición revisada para estudiantes. Cambridge: Cambridge University Press.

Hobbes, T. 1998. On the Citizen. Cambridge: Cambridge University Press. [Hay versión castellana en Hobbes, T. 1999. Tratado sobre el ciudadano, editado por J. Rodríguez Feo. Madrid: Trotta, 1999.]

Hoekstra, K. 2004. The de facto Turn in Hobbes's Political Philosophy. En Leviathan After 350 Years, editado por T. Sorell y L. Foisneau. Oxford: Oxford University Press, 34-73.

Jaume, L. 2007. Hobbes and the Philosophical Sources of Liberalism. En The Cambridge Companion to Hobbes's Leviathan, editado por P. Springborg. Cambridge: Cambridge University Press, 199-216.

Lee, D. 2016. Popular Sovereignty in Early Modern Constitutional Thought. Cambridge: Cambridge University Press.

Lucian. 1913. Hércules. En Works, editado por A. M. Harmon. London. [Hay versión castellana en Luciano 1983. Heracles, Obras I. Madrid: Gredos.]

Macpherson, C.B. 1962. The Political Theory of Possessive Individualism. Hobbes to Locke. Oxford: Oxford University Press. [Hay versión castellana en Macpherson, C.B. 2005. La teoría política del individualismo posesivo. De Hobbes a Locke. Madrid: Trotta.]

Parkin, J. 2005. Taming the Leviathan: The Reception of the Political and Religious Ideas of Thomas Hobbes in England 1640-1700. Cambridge: Cambridge University Press.

Pateman, C. 1988. The Sexual Contract. Cambridge: Polity Press.

Pateman, C. y Mills, C. 2007. Contract and Domination. Malden: Polity Press.

Pettit, P. 1997. Republicanism, A Theory of Freedom and Government. Oxford: Oxford University Press. [Hay versión castellana en Pettit, P. 1999. Republicanismo. Una teoría sobre la libertad y el gobierno. Barcelona: Paidós Ibérica.] 
Pettit, P. 2005. Liberty and Leviathan. Politics, Philosophy \& Economics 4 (1), 13151.

Pocock, J.G.A. 1957. The Ancient Constitution and the Feudal Law. Cambridge: Cambridge University Press. [Hay versión castellana en Pocock, J.G.A. 2011. La Ancient Constitution y el derecho feudal. Madrid: Tecnos.]

Skinner, Q. 1990. Thomas Hobbes and the Proper Signification of Liberty. Transactions of the Royal Historical Society 40, 121-51.

Skinner, Q. 1998. Liberty before Liberalism. Cambridge: Cambridge University Press. [Hay versión castellana en Skinner, Q. 2004. La libertad antes del liberalismo. Madrid: Taurus.]

Skinner, Q. 2008. Hobbes and Republican Liberty. Cambridge: Cambridge University Press. [Hay versión castellana en Skinner, Q. 2010. Hobbes y la libertad republicana. Buenos Aires: Editorial Universidad Nacional de Quilmes.]

Skinner, Q. 2018. From Humanism to Hobbes: Studies in Rhetoric and Politics. Cambridge: Cambridge University Press.

Springborg, P. 1995. Hobbes's Biblical Beasts, Leviathan and Behemoth. Political Theory 23 (2), 353-75.

Springborg, P. 2001. Republicanism, Freedom from Domination and the Cambridge Contextual Historians. Political Studies 49 (5), 851-76.

Springborg, P. 2009. The Paradoxical Hobbes, a Reply to Baumgold, 'The Difficulties of Hobbes Interpretation'. Political Theory 37 (5), 676-88.

Tuck, R. 1979. Natural Rights Theories: Their Origin and Development. Cambridge: Cambridge University Press. EP 